\title{
Impact of Curriculum Modifications on Access to the General Education Curriculum for Students With Disabilities
}

SUK-HYANG LEE

Ewha Womans University

MICHAEL L. WEHMEYER

JANE H. SOUKUP

SUSAN B. PALMER

University of Kansas

ABStRAct: This study investigated whether curriculum modifications predicted student and teacher behaviors related to the general education curriculum and if there were differences in ecological, student, and teacher variables depending on the presence of such curriculum modifications. The study observed 45 bigh school students with disabilities during instruction in core content areas. Findings indicated that there were significant differences in student and teacher variables depending on the presence of curriculum modifications. When curriculum modifications were provided, students were engaged in more academic-related responses and fewer competing behaviors and teachers were engaged in fewer classroom management activities. Implications and recommendations from these findings are provided pertaining to the importance and implementation of curriculum modifications for students with disabilities in general education settings.

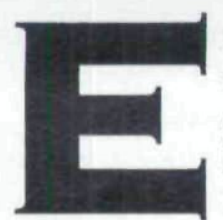
nabling students to gain access to and make progress in the general education curriculum has become a core requirement of federal law governing educational services for students with disabilities. The 1997 amendments to the Individuals With Disabilities Education Act (IDEA 97), and subsequently the 2004 amendments, required schools to institute policies and practices to promote involvement with and progress in the general education curriculum, including providing sup- plementary aids and services and special education services to students with disabilities to promote such outcomes (IDEA 2004, Sec.602[a][19], 1414[d]; Sec.602[34][A]). Consequently, research has been conducted evaluating practices intended to promote access to and examining factors related to students' academic progress in the general education curriculum. Such practices and factors typically examined include (a) specially designed instruction, including modifications to instructional practices and curricular materials; (b) student and teacher variables hypothesized to be 
related to curriculum access and academic progress; and (c) classroom ecological and setting factors.

Curriculum modifications have been identified as critical if students with disabilities are to achieve access to and make progress in the general education curriculum (Fisher \& Nancy, 2001; Janney \& Snell, 2000; Kame'enui \& Simmons, 1999; Nolet \& McLaughlin, 2000). Wehmeyer and colleagues (Wehmeyer, Lance, \& Bashinski, 2002; Wehmeyer, Lattin, \& Agran, 2001) proposed two types of curriculum modifications-curriculum adaptations and curriculum augmentations-that can be implemented to promote student access. Curriculum adaptations refer to modifications to the ways in which content is represented or presented or in which students engage with and respond to the curriculum. Such modifications do not alter the content in any way, but instead seek to provide multiple means for students to access and respond to the content, often achieved through incorporating principles of Universal Design for Learning (UDL; Rose \& Meyer, 2002; Wehmeyer et al.). UDL refers to the design of instructional materials and activities to make the content information accessible to all children (Rose \& Meyer). UDL promotes flexibility in representing content (how instructional materials present the content), presenting content (how educators deliver content), and demonstrating content mastery (how students provide evidence of their learning; Rose \& Meyer). Teachers achieve flexibility in representing and presenting content when they use several different formats, including text, graphics or pictures, digital and multiple media (audio or video), or performance formats (plays, skits) and when they use different means to deliver content information, including lectures, computerized visual presentations such as PowerPoint, role playing, or computer-mediated instruction. Similarly, students can provide evidence of their learning through reports, exams, portfolios, drawings, performances, oral reports, videotaped reports, and other alternative means.

Curriculum augmentations refer to efforts to augment or expand the general education curriculum to provide additional skills or strategies that help students succeed within the general education curriculum. In fact, curriculum augmentation strategies are useful for most students, as they involve teaching students learning-to-learn and meta-cognitive, or execurive processing strategies, that, in turn, enable students to engage more successfully with the content provided. So, again, the general education content is not altered at all by the use of curriculum augmentations, but instead additional content is added that teaches students strategies (e.g., learning-to-learn strategies, problem-solving skills, goal-setting skills, self-monitoring skills) that enable them to more effectively engage with the curriculum content (Lee et al., 2006).

\section{Classroom ecological and setting factors have also been shown to be important to student access to and progress in the general education curriculum.}

Lee, Wehmeyer, Palmer, Soukup, and Little (2008) investigated the impact of promoting selfdetermination as a form of curriculum augmentation on the access to the general education curriculum of high school students with disabilities. Similar to the studies cited previously, these authors found that curriculum adaptations and augmentations were rarely present in the instructional experiences of students with disabilities, but also found that students who were provided instruction to self-direct learning (e.g., curriculum augmentation) achieved goals linked to the general education curriculum at rates higher than expected. Lee et al. also found preliminary evidence that student self-determination level predicted the presence of behaviors conducive to greater access and progress; specifically, increased student engagement and decreased competing (e.g., nonacademic) behaviors. Descriptive analysis also revealed that this pattern of student behaviors (increased student engagement and decreased competing behaviors) was observed when curriculum modifications were present.

In addition to curriculum modifications such as curriculum adaptations or augmentations, student and teacher variables are important to promote student involvement with and progress in the general education curriculum. Observational methodologies based on ecobehavioral assessment have been widely used to investigate student and teacher variables and classroom settings in typical classroom setrings (Ross, Singer-Dudek, \& Greer, 
2005; Salend, 2000). Ecobehavioral assessment "is designed to reveal sequential and concurrent interrelationships between environmental stimuli and a child's responding" (Greenwood, Schulte, Kohler, Dinwiddie, \& Carta, 1986, p. 71). Ecobehavioral assessment can provide a "portrait" of a target setting or program by revealing detailed ecological and ecobehavioral data in a natural context (Brown, Odom, Li, \& Zercher, 1999). Ecobehavioral assessment also has been employed successfully in research examining school effectiveness in classroom settings (Greenwood, Carta, Arreaga-Mayer, \& Rager, 1991; Kamps, Leonard, Dugan, Boland, \& Greenwood, 1991; Logan, Bakeman, \& Keefe, 1997; Logan \& Keefe, 1997). In particular, it has been used to investigate student engagement time, instructional strategies, and context factors in group comparison studies for a variety of situations, including observing the same participants in different education settings such as homeschool versus public school (Duvall, Delquadri, \& Ward, 2004; Katz, Mirenda, \& Auerbach, 2002; Woolsey, Harrison, \& Gardner, 2004) and observing different student groups (e.g., students with disabilities vs. their peers; students from low-SES families vs. high-SES families, at-risk students vs, nonrisk students) in the same setting, typically a general education classroom (Greenwood, 1991; Greenwood, Delquadri, \& Hall, 1989; McDonnell, Thorson, \& McQuivey, 2000; Wallace, Anderson, Bartholomay, \& Hupp, 2002). Furthermore, ecobehavioral assessment has been used to assess and evaluate teacher behaviors and performance in classroom settings (Roberson, Woolsey, Seabrooks, \& Williams, 2004a, 2004b; Ross et al.).

Research findings on student and teacher variables from these and similar studies using ecobehavioral observation methodologies show a well-established link berween student achievement and time spent in academic engagement and instructional factors (Brophy \& Good, 1986; Greenwood, 1991; Salend, 2000; Wallace et al., 2002) and show that the academic engagement of students with disabilities is significantly higher during teacher-directed instruction than during seatwork in both resource room and general education settings (Friedman, Cancelli, \& Yoshida, 1988). In addition to teacher instructional behaviors, this line of research has identified teacher at- tention as an important variable influenćing desirable and undesirable student behaviors (Vyse \& Mulick, 1988). For example, an ecobehavioral examination of high school students with disabilities by Wallace et al. found that students with disabilities were more often the focus of teachers' attention than were students without disabilities. Lee, Soukup, Little, and Wehmeyer (2009) also reported that student and teacher variables (i.e., student academic/competing response, teacher instruction and management behaviors, and teacher focus) were strong predictors of access to the general education curriculum for students with intellectual disability.

Classroom ecological and setting factors have also been shown to be important to student access to and progress in the general education curriculum. Wehmeyer and colleagues conducted several studies examining the degree to which students with intellectual disability are (a) engaged with the general education curriculum and (b) provided supports needed to achieve such access, as well as examining student, setting, and classroom ecological factors related to such access. Wehmeyer, Lattin, Lapp-Rincker, and Agran (2003) observed 33 middle school students with intellectual disability for a total of 6,585 min across general education and self-contained settings. During $70 \%$ of the observed intervals, students were engaged in a task related to a school district standard. This varied, however, by level of disability. Students with mild cognitive impairments were engaged in a task linked to a standard in $87 \%$ of intervals, whereas students with more severe intellectual impairments were doing so during only $55 \%$ of intervals. Further, students observed in the general education classroom were working on tasks linked to a standard in $90 \%$ of intervals, whereas students observed in self-contained settings engaged in tasks related to a standard in only $50 \%$ of the intervals. Wehmeyer et al. found that the percentage of intervals in which students used some form of curriculum modification was just $2.78 \%$ of observed intervals, with students using some form of curriculum augmentation in only $0.15 \%$ of the intervals.

These findings were mirrored in a study by Soukup, Wehmeyer, Bashinski, and Bovaird (2007), who observed 19 elementary students with intellectual and developmental disabilities 
for a total of $1,140 \mathrm{~min}$ and recorded the occurrence of curriculum adaptations and augmentations. Students with intellectual and developmental disabilities in general education classrooms worked on grade level standards $(60 \%$ of the intervals) more than three times the frequency of intervals in which they worked on a standard linked to just any grade ( $20 \%$ of intervals) or on individualized education program (IEP) objectives ( $23 \%$ of objectives). Curriculum adaptations were observed, however, in only $18 \%$ of intervals and no occurrences of curriculum augmentations were observed. Soukup and colleagues also examined classroom setting variables (e.g., general education vs. self-contained classroom); classroom ecological variables such as instructional grouping strategies (e.g., whole class, small group, one-on-one, independent, and no instruction); and classroom physical arrangement variables (entire group, divided group, and individual group) on student access. When analyzed together, classroom setting and physical arrangements were significant predictors of access (students educated in general education classrooms and in large group physical arrangements having the highest access), and small group instructional grouping strategies were also predictive of greater access. Both Wehmeyer et al. (2003) and Soukup et al. found that setting - that is, where students were receiving instruction-was predictive of their relative access to the general education curriculum. In essence, students receiving instruction in the general education classroom were significantly more likely to be working on activities linked to general education content standards, although they were doing so without the types of curriculum modifications that research suggests is important for academic progress.

The relative absence of curriculum modifications, including either curriculum adaptations or curriculum augmentations, to promote access to the general education curriculum by students with intellectual and developmental disabilities is, obviously, problematic. Research by Dymond and Russell (2004) suggested, moreover, that the implementation of such modifications may not be any greater for students with mild disabilities. These researchers examined the impact of grade and disability on interactions among students, teachers, and the environment in elementary gen- eral education classrooms and found that curriculum modifications of any kind were almost nonexistent for students with mild disabilities, though they were used some with students with severe disabilities. In sum, data from these studies suggested that curriculum modifications were rarely implemented, in spite of the fact that they have been widely considered as a best practice to enhance access to and progress in the general education curriculum.

Although the research described has provided information about some of the factors that impact student access to and progress in the general education curriculum, there are other relationships that have not, to this point, been investigated. Research has shown that factors such as classroom setting and physical arrangements influence access collectively even if they do not do so individually. It is likely that most of these factors - the design of the delivery of the content, instructional strategies, curriculum modifications, classroom and ecological factors, and teacher and student factorsinteract in ways that influence outcomes such as access and progress. This study sought to expand the knowledge base by examining the reciprocal relationships between the presence or absence of curriculum modifications on both teacher and student behaviors. The research will replicate aspects of other studies, including examining the presence of curriculum modifications, but will provide new knowledge with regard to the relationship of such modifications with both teacher and student behavior and ecological variables.

This study investigated the degree to which curriculum modifications directly predict or affect student or teacher behaviors that are important to promoting access to and progress in the general education curriculum, as well as examining differences in other ecological, student, and teacher variables as a function of the presence or absence of curriculum modifications using ecobehavioral examination with the following research questions:

1. Does the presence of curriculum modifications predict student or teacher behaviors?

2. Are there any differences observed in student/teacher behaviors and ecological variables depending on the presence of curriculum modifications? 
We would predict that the presence of curriculum modifications would be positively related to more positive student academic behaviors and teacher variables pertaining to classroom management time, and negatively related to student behaviors competing with academic behaviors.

\section{METHODS}

\section{PARTICIPANTS AND SETTING}

Participants were 45 students with disabilities recruited from 11 campuses at 7 suburban school districts in the Midwest who met the following two criteria: high school students with disabilities (a) receiving special education services and (b) receiving instruction in core content areas (e.g., English, math, social studies, or science) in a general education classroom. Students ranged in age from 14.2 to 19.2 years $(M=16.36$ years, $S D=1.22)$, and in Grades 9 through 12. Twenty-nine students were male $(M=16.30$ years, $S D=1.27)$ and 16 students were female $(M=16.47$ years, $S D=$ 1.15). Three fourths of the overall sample $(n=34)$ received special education services under the learning disability category; 7 students $(16 \%)$ were served under the Other Health Impairment category $(\mathrm{OHI})$, including students with attention deficit disorder or attention deficit hyperactivity disorder (ADD/ADHD); 3 students (7\%) received special education services under the emotional and/or behavioral disorders category (EBD); and 1 student $(2 \%)$ was served under the autism category. Thirty students $(67 \%)$ were White, followed by Hispanic/White (18\%), Native American/Alaskan Native (4\%), Asian or Pacific Islander (4\%), and African American (2\%). To recruit students, the primary researcher contacted districtlevel special education administrators, who were asked to identify students who met the criteria of receiving special education services and receiving instruction on core content areas in the general education classrooms. To ensure confidentiality, student names were not released to the researcher, and, instead, the researcher was referred to special education teachers responsible for the educational programs of potential research participants. When these teachers consented to participate, they were asked to obtain informed consents from students who met the criteria and their parents who were responsible for the students. Students were provided a gift card for participating in the study.

Current (e.g., within 2 years) scores from standardized intelligence tests were not available for most students. To provide some indicator of student level of functioning, Soukup and colleagues (2007) asked teachers to respond to items asking them to rate, on a Likert-type scale ranging from "1" (no supports needed) to " 5 " (total support needed), the degree to which students needed supports to function overall (e.g., independent living, daily care, community integration, etc.), referred subsequently to as Overall Support Needs, and to acquire new knowledge and skills, referred subsequently to as Learning Support Needs. This procedure was replicated in this study, and participants had the same mean in both Overall Support Need and Learning Support Need scores (2.91), with a median score of 3 .

Students received instruction in English $(n=$ $11,24 \%)$; math $(n=11,24 \%)$; social studies ( $n=$ $14,31 \%)$; or science $(n=9,20 \%)$ classes. Twenty-five students $(56 \%)$ were under special education teachers' direct supervision between 1 and $3 \mathrm{hr}$ of the instructional day. The typical educational setting for about three fourths of students in the overall sample ( $n=33$ ) was the general education classroom, although fully half of the students spent 3 to $5 \mathrm{hrs}$ on average per day with their nondisabled peers.

Participating students were observed in one of their core content general education classes. During observation, 29 general education teachers were involved in the study. Thirteen teachers were male and 16 teachers were female. The teachers ranged in age from 23 to 49 years $(M=34.2$ years, $S D=9.09$; excluding 7 teachers who declined to provide their age). The average number of years teaching for the general education teachers was 8.2 years $(S D=6.93)$. Seven teachers taught English $(24.1 \%)$ and math $(24.1 \%)$, respectively. Five teachers taught science $(17.2 \%)$ and 10 teachers taught social studies $(34.5 \%)$. Twenty-seven $(93.1 \%)$ of the 29 teachers had an undergraduate general education degree and 9 of them $(31.0 \%)$ had a Master's degree in General Education. There were no teachers who had both a special and general education undergraduate degree. 
Teachers were asked about their preparation for teaching and whether or not they had experience with curriculum modifications. All general education teachers had received some information or training about curriculum modifications for students with disabilities and most teachers received it during their undergraduate training ( $n=$ $21,72.4 \%)$; from colleagues $(n=20,69 \%)$, or through a district inservice $(n=19,65.5 \%)$. In terms of time spent on communication for collaboration with special education teachers, $55 \%$ ( $n=$ 16) of the general education teachers communicated with special education teachers more than once a week or every day.

Fourteen special education teachers were also involved in this study. Two were male and 12 were female. The mean age of the special education teachers was 41.6 years $(S D=9.16$, range from 28 to 59 years; excluding 3 teachers who declined to provide their age). The average number of years teaching for the special education teachers was 13.2 years $(S D=9.26)$. Eleven teachers $(78.6 \%)$ of the 14 had a Master's degree in Special Education, and of them $8(57 \%)$ had an undergraduate general education degree. With regard to their previous training about or experiences with curriculum modifications, special education teachers most frequently mentioned graduate training ( $n=11,78.6 \%)$, colleagues $(n=10$, $71.4 \%$ ); conferences/workshop ( $n=10,71.4 \%$ ); and district inservice $(n=8,57.1 \%)$ as the means by which they received training or gained information about curriculum modifications. Similar to the responses from general education teachers, $57.1 \%(n=8)$ of special education teachers communicated with general education teachers more than once a week or every day.

\section{PROCEDURES}

After obtaining parental, teacher, and student consent, the lead researcher conducted initial brief interviews with each special education teacher to collect data about each student (e.g., age, gender, grade, IEP goals, and level of support needs) and their course schedules, the latter for arranging classroom observations. Informed consent to participate was also obtained from each general education teacher in the content class in which students would be observed. All participat- ing students were observed using a momentary time sampling method with a data collection system (described subsequently) in a core content general education class.

\section{INSTRUMENTATION}

Data regarding student access to the general education curriculum were collected using a Windows PC-based time sampling data collection system called the Access CISSAR. The Access CISSAR is an expanded version of a direct observational system, the MainStream Version of the Code for Instructional Structure and Student Academic Response (MS-CISSAR; Carta, Greenwood, Schulte, Arreaga-Mayer, \& Terry, 1988), and a component of the EcoBehavioral Assessment System Software (EBASS), designed to collect classroom observational data (Greenwood, Carta, Kamps, Terry, \& Delquadri, 1994).

The MS-CISSAR focuses on an individual student as an observer's target and structures the collection of data, using a momentary time-sampling methodology, on 105 individual codes in 13 categories of variables, across 3 conceptual groupings: classroom ecology (5 categories), teacher behavior ( 5 categories), and student behavior ( 3 categories; see Figure 1). Using the MS-CISSAR, data are collected in each of the 13 categories of variables during a $60-\mathrm{s}$ interval comprised of 20-s observation intervals. One event may be recorded for each of the 13 categories during each interval, and data entry is limited to four active keys to reduce the probability of erroneous entries. The duration of data collection sessions using the MS-CISSAR is flexible and may be structured, in full-minute increments, as a researcher deems appropriate.

The MS-CISSAR was subjected to rigorous technical scrutiny during its development and field-testing. Test-retest reliabilities averaged .85 overall (Greenwood et al., 1997). The MS-CISSAR's divergent validity was demonstrated through the correlation of students' higher levels of academic responding in the classroom with posttest gains on the Metropolitan Achievement Test-Basic Scale (Greenwood, Arreaga-Mayer, \& Carta, 1994). In addition, Kamps, Greenwood, and Leonard (1991) documented treatment validity in an investigation with students with autism. 


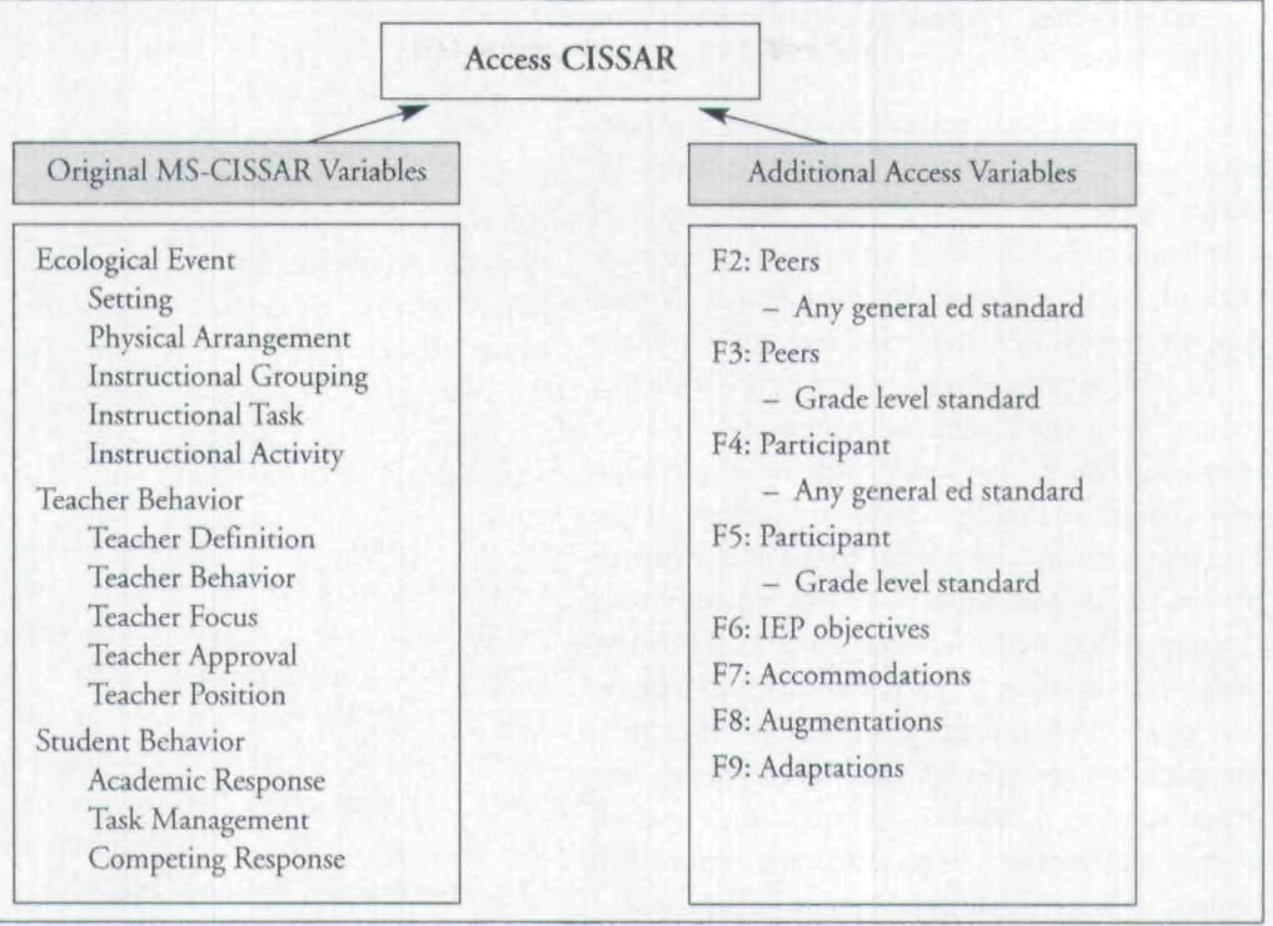

Bashinski and Wehmeyer (2002) expanded the MS-CISSAR to collect additional data regarding when and how opportunities were made available for students to access the general education curriculum. This expanded version, called the Access CISSAR, includes all 13 of the original classroom ecological, teacher behavior, and student behavior categories from the MS-CISSAR, and 102 of the original 105 variables (three codes were eliminated from the teacher behavior category). In addition to the original MS-CISSAR variables, the Access CISSAR was designed to capture data indicating the degree to which students had access to the general education curriculum (see Figure 1). These observational categories were derived from a model for curriculum access proposed by Wehmeyer et al. (2002) and from codes developed by Wehmeyer et al. (2003). Each of these codes was linked to a "virtual toggle switch" recorded in the Access CISSAR by hitting the F2 through F9 function keys on a computer's keyboard. Each toggle was set at "off" or "on" before the start of each observation. For intervals in which a toggle was on, the variable was counted as present. Toggles could be switched on or off at any time during an observation if any aspect of the situation changed, and the entire interval in which a change was made reflected such. The "access codes" were

a. F2-whether a participant's peers were engaged in a task linked to any general education standard (that is, any standard from a grade lower than the student's actual grade level).

b. F3-whether a participant's peers were engaged in a task linked to a grade-level standard.

c. F4-whether a participant (e.g., the student with a disability being observed) was engaged in a task linked to any general education standard.

d. F5-whether a participant was engaged in a task linked to a grade-level standard.

e. F6-whether a participant was engaged in a task linked to an IEP goal.

f. F7-whether accommodations were in place to support the student. 
g. F8-whether curriculum augmentations were observed.

h. F9-whether curriculum adaptations were provided.

The code identified as F7 recorded the presence of any accommodations. Such accommodations were defined as the provision of supplementary aids and services, such as the presence of a paraprofessional, engagement in peer support, the use of a note-taker and so forth. If the F7 (accommodations in place) toggle was switched to "on," then one of eight additional codes was selected describing the specific type of accommodation. These are listed in Table 1 . Similarly, if the F8 (augmentations observed) toggle was switched to "on," additional codes were selected describing the type of augmentation (see Table 1). The same design was in place when the curriculum adaptation code (F9) was toggled to "on," at which time the code for any of eight adaptations (e.g., adjusted reading demand-the readability level of written materials the target student is expected to process is lowered, adjusted cognitive demandsthe amount of content the target student is expected to complete is reduced, etc.; see Table 1). All Access CISSAR variables could be reentered or changed at any time during data collection. The observer could simultaneously code as many access-related variables as were observed. The Access CISSAR has been used in several studies to examine student, teacher, and classroom ecological variables pertaining to access to the general education curriculum for students with disabilities (Lee et al., 2009; Soukup et al., 2007).

\section{RELIABILITY TRAINING}

The lead researcher, who was the primary data collector, received one-on-one training from a person who had been trained to mastery on the MS-CISSAR. Training began with an "instrument calibration" process; a test of an observer's capacity to collect data from a videotaped classroom simulation in agreement with a standard set by the original MS-CISSAR's software developers. Reliability training for the MS-CISSAR also included "live" in-school practice and in-school reliability sessions. After receiving an overall reliability rating of $97.49 \%$ agreement with a trainer for three in- school training sessions (a total of $61 \mathrm{~min}$ ) on the MS-CISSAR, the primary observer received training on the Access CISSAR, obtaining a reliability score of $97.85 \%$ for that version including Access CISSAR along with MS-CISSAR. The trainer also served as a second observer for this study. Another second observer had been trained to mastery using the same training process as discussed previously. Overall reliability rating of agreement for three inschool sessions (a total of $86 \mathrm{~min}$ ) between primary observer and the second observer was $95.75 \%$.

\section{DATA COLLECTION}

All 45 students were observed in their general education class for a total of 1,350 $\mathrm{min}$ (30 min for each student). Data collection began and was completed during the fall semester of the school year. Immediately before each data collection session, the researcher (and reliability coder, if scheduled) met with and asked the teacher(s) about that day's lesson and activities using an observation information protocol including questions about the day's lesson, objectives, main activities, any curriculum/activities modifications for target student, content areas, and standards. This enabled the researcher to determine not only what content-related standards were to be addressed by that day's lesson, but also to set the Access CISSAR codes pertaining to whether tasks were linked to any grade level (F2, F4) or grade level content standards (F3, F5); whether tasks were linked to an IEP goal or objective (F6); and what types of accommodations (F7), augmentations (F8), or curriculum adaptations (F9) were to be used for the start of the observation. Changes in any of these indicators of access during any given observation (for example, the addition of an adaptation where one had not existed at the start of the observation) resulted in a change to the toggle for that and subsequent intervals.

During each session, the observer was seated to record data where she was able to hear and see a study participant, but so as not to intrude on instructional activities. First, the observer entered student information required by the Access CISSAR software and coded the initial Access toggle settings, as indicated, before beginning the coding interval. The observer then began the formal cod- 


\begin{tabular}{|c|c|c|c|c|c|c|c|}
\hline \multirow{2}{*}{$\frac{T \#}{\text { F2 }}$} & \multirow{2}{*}{$\begin{array}{l}\text { Toggle Description } \\
\text { PEERS - any general ed standard }\end{array}$} & \multicolumn{2}{|c|}{$\begin{array}{c}\text { Total } \\
\text { Intervals } \\
\left(\mathrm{N}^{a}=1350\right) \\
\text { Frequency }(\%)\end{array}$} & \multicolumn{2}{|c|}{$\begin{array}{c}\text { No CM: } \\
\text { Only F4+F5 } \\
\left.\mathrm{N}^{b}=363\right) \\
\text { Frequency (\%) }\end{array}$} & \multicolumn{2}{|c|}{$\begin{array}{c}\text { CM: } \\
\text { Adaptations } \\
\left(\mathrm{N}^{\mathrm{c}}=281\right) \\
\text { Frequency }(\%)\end{array}$} \\
\hline & & 30 & $(2.2)$ & 30 & (8.3) & 0 & \\
\hline F3 & PEERS - grade level standard & 1,293 & $(95.8)$ & 333 & $(91.7)$ & 281 & $(100)$ \\
\hline $\mathrm{F} 4$ & PARTICIPANT - any general ed standard & 293 & $(21.7)$ & 72 & $(19.8)$ & 72 & $(25.6)$ \\
\hline F5 & PARTICIPANT - grade level standard & 1,026 & $(76.0)$ & 291 & $(80.2)$ & 207 & $(73.7)$ \\
\hline F6 & PARTICIPANT - IEP objectives & 192 & $(14.2)$ & 75 & $(20.7)$ & 33 & (11.7) \\
\hline \multirow[t]{9}{*}{ F7 } & Accommodations (at least one of the following) & 843 & $(62.4)$ & 0 & & 159 & $(56.6)$ \\
\hline & 1 - Paraprofessional & 840 & $(62.2)$ & 0 & & 156 & $(55.5)$ \\
\hline & 2 - Peer Support & 0 & & 0 & & 0 & \\
\hline & 3 - Note-taker & 0 & & 0 & & 0 & \\
\hline & 4-Environmental Adjustment & 0 & & 0 & & 0 & \\
\hline & 5 - Extended Time & 0 & & 0 & & 0 & \\
\hline & 6-Redistributed time & 0 & & 0 & & 0 & \\
\hline & 7-Assistive technology & 0 & & 0 & & 0 & \\
\hline & 8 - Other & 0 & & 0 & & 0 & \\
\hline \multirow[t]{6}{*}{ F8 } & Augmentations (at least one of the following) & 0 & & 0 & & 0 & \\
\hline & 1 - Strategies for learning & 0 & & 0 & & 0 & \\
\hline & 2 - Strategies for test-taking & 0 & & 0 & & 0 & \\
\hline & 3-Strategies for organization & 0 & & 0 & & 0 & \\
\hline & 4-Strategies for self-regulation & 0 & & 0 & & 0 & \\
\hline & 8 -Other & 0 & & 0 & & 0 & \\
\hline \multirow[t]{9}{*}{ F9 } & Adaptations (at least one of the following) & 281 & $(20.8)$ & 0 & & 281 & (100) \\
\hline & 1 - Adjusted reading demand & 0 & & 0 & & 0 & \\
\hline & 2 - Adjusted cognitive demand (not reading) & 23 & $(1.7)$ & 0 & & 23 & $(8.2)$ \\
\hline & 3 - Non-print content & 22 & (1.6) & 0 & & 22 & $(7.8)$ \\
\hline & 4 - Content through technology & 47 & (3.5) & 0 & & 47 & $(16.7)$ \\
\hline & 5 - Enhanced content & 234 & $(17.3)$ & 0 & & 229 & $(81.5)$ \\
\hline & 6 - Nontraditional response(s) to instruction & 0 & & 0 & & 0 & \\
\hline & 7 - Nontraditional instructional materials & 0 & & 0 & & 0 & \\
\hline & 8 - Other & 0 & & 0 & & 0 & \\
\hline
\end{tabular}

Note: The numbers add up to more than each $\mathrm{N}^{\mathrm{a}}, \mathrm{N}^{\mathrm{b}}, \mathrm{N}^{\mathrm{c}}$ because there are overlapping categories.

ing session by entering information that corresponded to the situation observed using the MSCISSAR protocol "look, record, and rest" pattern.

\section{DATA ANALYSIS}

Multilevel regression was employed to investigate the degree to which curriculum modifications directly predict or affect student or teacher behaviors that are important to promoting access to and progress in the general education curriculum. Differences in all other ecological, student, and teacher variables as a function of the presence or absence of curriculum modifications were exam- ined through descriptive analyses along with ANOVA.

Regression Analysis. For the 19 observations ( $42 \%$ of all observations), interrater reliability was obtained through the MS-CISSAR reliability check report (Greenwood \& Hou, 1995). Cohen's Kappa statistic (Sax, 1997) was used to calculate an index of interobserver agreement. Values higher than Kappa $=.60$ are generally considered to be adequate levels of agreement (Hartmann \& Woods, 1982). Because data from each of the 30 observation cycles produced in a 30-min observation (Level 1) were nested within each student (Level 2), multilevel (two-level) regression analyses 
were employed to analyze the data. The multilevel model is appropriate to analyze the data in this research for several reasons. First, it provides an efficient framework for analyzing a nested data structure (Guo \& Zhao, 2000; Singer, 1998; Singer \& Willett, 2003). As aforementioned, the 45 students were observed during core content areas for 30-min intervals. As such, each of the 30 observation intervals (Level 1) was nested within each student (Level 2). Second, multilevel modeling corrects biases in parameter estimates and standard error resulting from clustering that occurs when observations are correlated within clusters (Browne \& Rasbash, 2004; Guo \& Zhao). Given the nested structure of the data, the observation intervals from the same students are likely more correlated (Rabe-Hesketh, Toulopoulou, \& Murray, 2001; Rasbash, 2007) than those from different students, when differences regarding severity of disability, support needs, and the classroom context (i.e., amount of time in general education classroom) are considered. In this case, applying a simple regression technique, which is based on independence between observations (Kenny \& Judd, 1986; Rabe-Hesketh et al.), to the clustered data results in inefficient and biased parameter estimates by underestimating the standards of regression (Browne \& Rasbash; Carvajal, Baumler, Harrist, \& Parcel, 2001; Rasbash). Therefore, multilevel models can be used for this analysis because it corrects possible biased inferences by dealing with data correlated within clusters and possible differences unobserved related to severity of disability, support needs, and other natural class contexts. Third, it partitions the variance in the dependent variable into portions associated with each level (Guo \& Zhao.).

In terms of sample size for multilevel regression, Kreft (1996) suggested a rule of thumb called the " $30 / 30$ rule" from the various simulations reviewed. It means that at least 30 groups (Level 2) with at least 30 individuals (Level 1) are needed for multilevel modeling. Having at least a sample of 30 at Level 2 was recommended when the researcher is interested in contextual effects (Maas \& Hox, 2004), even though a sample of 50 would be better. Therefore, the sample size of this study (30 intervals [Level 1] nested within 45 students [Level 2]) is appropriate even though it is not ideal.
Predictor and Dependent Variables. Predictor variables involved two different conditions: (a) a No Curriculum Modifications condition (No $\mathrm{CM}$ group; i.e., any intervals in which students were engaged in tasks linked with off-grade [Only F4] or on-grade level standards [Only F5] without any curriculum modifications present) and (b) a Curriculum Modifications condition (CM group; i.e., intervals in which students were engaged in tasks linked to an off-gradelon-grade level standard in which any curriculum modifications were present including only accommodations provided [Only F7], only adaptations provided [Only F9], and both accommodations and adaptations provided [Both F7 and F9]). Dependent variables included student variables (i.e., academic response, task management, competing response) and teacher variables (i.e., instructional behavior, management behavior, and teacher focus) from the Access CISSAR coding process.

To provide a baseline against which we can compare more complex models, we used the unconditional means model (null model or empty model) that examined variation in interval (Level 1) outcomes across students. Based on the unconditional mean model, which does not have any predictor, the following Level 2 Predictor (or variable) model was provided to examine the effect of student-level predictors, including intervals in which students are engaged in tasks linked with off-grade level standards without any curriculum modifications (Only F4), intervals in which students are engaged in tasks linked with on-grade level standards without any curriculum modifications (Only F5), only accommodations provided (Only F7), only adaptations provided (Only F9), and both accommodations and adaptations provided (Both F7 and F9). There were no curriculum augmentations (F8) observed. Given that all dependent variables were dichotomous categorical variables, multilevel (two-level) regression analyses for categorical outcomes using Mplus was used to find the best fit based on the above model.

Finally, ecological, student, and teacher data were analyzed depending on the presence of curriculum modifications: No Curriculum Modifications (No CM group) and Curriculum Modifications (CM group). Also, one-way ANOVA was conducted to examine if there were significant differences between the No CM and CM 
group intervals across student and teacher variables.

\section{RESULTS}

Multilevel regression and descriptive analysis along with group differences analysis indicated that providing curriculum modifications predicted student behaviors (i.e., academic response, compering response), and there were significant differences between the No CM and the CM groups especially across student and teacher variables. As an index of the interrater reliability on all observations, the average Cohen's Kappa for $42 \%$ of the 45 observation data in which two coders recorded data simultaneously was .896 , ranging from .792 to 968 .

\section{CURRICULUM MODIFICATIONS AS A PREDICTOR OF STUDENT BEHAVIOR}

A best-fit model multilevel regression analysis was used to investigate whether curriculum modifications predict student and teacher behaviors that can affect access to the general education curriculum. Table 2 provides outcomes for the comparison of the fit between the unconditional means model and the Level 2 predictor model. There were no significant differences between the unconditional models and Level 2 predictor model on teacher management $\Delta \chi^{2}(5, n=1350)=$ 7.67, $p=0.18$, and teacher focus $\Delta \chi^{2}(1, n=$ $1350)=2.18, p=0.14$ variables, although all Level 2 predictors had a negative relationship with the teacher management variable and Only F4 (intervals linked to off-grade level standards) had a negative relationship with the teacher focus. For student management and teacher instruction variables, the model did not converge because of a lack of sufficient variation in intercept and slope, and it meant that simplifying the model was appropriate (Moineddin, Matheson, \& Glazier, 2007). However, there were significant differences between the unconditional means model and the Level 2 predictor model on two student variables: the student academic response $\Delta \chi^{2}(4, n=1350)$ $=12.59, p<.01$ and competing response $\Delta \chi^{2}(3$, $n=1350)=10.27, p<.02$ variables, as Lee et al. (2008) had identified previously. In terms of student academic responses, the Only F4 (intervals linked to off-grade level standards) variable in the No CM group had a positive relationship with student academic response. The Only F5 (intervals linked to on-grade level standards) variable did not have any relationship with academic response. On the other hand, all variables - Only F7 (only accommodations provided), Only F9 (only adaptations provided), and Both F7 and F9 (both accommodations and adaptations provided) - in the CM group had a positive relationship with the student academic response. This trend is opposite with the case of the student competing response. In the No CM group intervals, both Only F4 (intervals linked to off-grade level standards) and Only F5 (intervals linked to on-grade level standards) variables had a positive relationship with the student competing response. However, in the case of the CM group, only one variable, Only F7 (only accommodation provided) had a positive relationship with the competing response. As seen in Table 1, among the sub-toggles for F7 (accommodations), only paraprofessional support was observed, and it dominated with $62.2 \%$ (840 intervals) of overall intervals in which the use of a paraprofessional was observed. (There were no sub-toggles identified for the remaining 3 intervals in which the F7 toggle was on.) In sum, the presence of curriculum modifications predicted increased student engagement and decreased competing (e.g., nonacademic) behaviors that would disrupt learning, whereas curriculum modifications were not significant predictors for teacher behaviors.

\section{ECOLOGICAL, STUDENT, AND TEACHER VARIABLES}

As mentioned previously, descriptive statistics (e.g., frequencies and percentage) about ecologi$\mathrm{cal}$, student, and teacher variables were analyzed depending on the presence of curriculum modifications (see Tables $3,4, \& 5$ ). The No CM group included 363 intervals in which Only F4 (intervals linked to off-grade level standards) and Only F5 (intervals linked to on-grade level standards) were observed without any curriculum modifications. The CM group included 281 intervals in which F9 (adaptations) were provided with offgrade or on-grade level standards including Only F9 (only adaptations provided) and Both F7 and 


\begin{tabular}{|c|c|c|c|}
\hline & Level 2 Predictors & $\begin{array}{c}\text { Student } \\
\text { Academic } \\
\text { Response } \\
\left.\mathrm{R}^{2}=.31\right) \\
\text { Estimates }^{\prime}(\mathrm{SE})\end{array}$ & $\begin{array}{c}\text { Student } \\
\text { Competing } \\
\text { Response } \\
\left(\mathrm{R}^{2}=.28\right) \\
\text { Estimates }^{2} \text { (SE) }\end{array}$ \\
\hline \multirow{2}{*}{$\begin{array}{l}\text { No curriculum } \\
\text { Modification } \\
\text { (No CM) }\end{array}$} & $\begin{array}{l}\text { Off-grade standard activity } \\
\text { (Only F4) }\end{array}$ & \multirow[t]{2}{*}{$0.197(0.091)^{* *}$} & $0.289(0.123)^{* *}$ \\
\hline & $\begin{array}{l}\text { On-grade standard activity } \\
\text { (Only F5) }\end{array}$ & & $0.565(0.173)^{* * *}$ \\
\hline \multirow{6}{*}{$\begin{array}{l}\text { Curriculum } \\
\text { Modification } \\
\text { (CM) }\end{array}$} & $\begin{array}{l}\text { Only accommodations provided } \\
\text { (Only F7) }\end{array}$ & $0.398(0.189)^{* *}$ & \multirow[t]{3}{*}{$0.685(0.206)^{* *+}$} \\
\hline & $\begin{array}{l}\text { Only adaptations provided } \\
\text { (Only F9) }\end{array}$ & $0.506(0.179)^{* * *}$ & \\
\hline & $\begin{array}{l}\text { Both accommodations and adaptations } \\
\text { provided } \\
\text { (Both F7 and F9) }\end{array}$ & $0.439(0.190)^{* *}$ & \\
\hline & $\Delta$ ChiSquare $\left(\Delta \chi^{2}\right)$ & 12.59 & 10.27 \\
\hline & df & 4 & 3 \\
\hline & $p$-value & $<0.01^{* * *}$ & $<0.02^{* *}$ \\
\hline
\end{tabular}

${ }^{\mathrm{a}}$ Completely Standardized Estimates.

${ }^{* *} p<.05 ;{ }^{* * *} p<.01$.

F9 (both accommodations and adaptations provided). Only F7 (only accommodations provided) were excluded from the CM group in order to compare the No CM group with the pure CM group that represents intervals including real and meaningful curriculum modifications considering the following concerns related to F7 (accommodations) variable:

a. Most curriculum modifications were F7 (accommodations; $62.4 \%$ ) and there was no F8 (curriculum augmentations).

b. Most F7 (accommodations) represented simply presence of a paraprofessional $(62.2 \%)$ without active support.

c. In the Only F7 (only accommodations provided) variable, paraprofessional support predicted the student competing response as seen in the result of the multiple regression analysis.

Ecological Events Intervals. Table 3 presents descriptive statistics of ecological event intervals observed with regard to the classroom physical ar- rangement, instructional grouping, instructional task, and instructional activity (i.e., subject matter) variables. In terms of physical arrangement, the entire group variable (i.e., when target student is located within the same general seating arrangement as all other students in the classroom) was the most frequently observed arrangement in both the No CM and CM groups. However, the entire group variable was more frequently observed $(94.3 \%)$ in the $\mathrm{CM}$ group than in the No CM group (72.7\%). On the other hand, intervals recording a divided group variable were observed about five times more $(27.3 \%)$ in the No CM group compared with that of the $\mathrm{CM}$ group $(5.7 \%)$. There was not a single interval in which individual group arrangement was observed in both the No CM and CM groups. With regard to instructional grouping, the whole class variable (i.e., when target student is receiving the same instruction as all other students) was the most frequently observed both in the No CM and CM groups, although whole class in the $\mathrm{CM}$ group $(80.1 \%)$ was observed more than that of the No CM group $(63.1 \%)$. On the other hand, the 
TABLE 3

Descriptive Statistics of Ecological Event Intervals Observed

\begin{tabular}{|c|c|c|c|c|c|c|}
\hline \multirow{3}{*}{$\frac{\text { Variable Description }}{\text { Physical Arrangement }}$} & \multirow{2}{*}{\multicolumn{2}{|c|}{$\begin{array}{l}\begin{array}{l}\text { Total Intervals } \\
(\mathrm{N}=1350)\end{array} \\
\text { Frequency (\%) }\end{array}$}} & \multirow{2}{*}{\multicolumn{2}{|c|}{$\begin{array}{c}\text { No CM: } \\
\text { Only F4+F5 } \\
(\mathrm{N}=363) \\
\text { Frequency }(\%)\end{array}$}} & \multirow{2}{*}{\multicolumn{2}{|c|}{$\begin{array}{c}\text { CM: } \\
\text { Adaptations } \\
(\mathrm{N}=281) \\
\text { Frequency }(\%)\end{array}$}} \\
\hline & & & & & & \\
\hline & & & & & & \\
\hline Entire group & 1,042 & $(77.2)$ & 264 & $(72.7)$ & 265 & (94.3) \\
\hline Divided group & 308 & $(22.8)$ & 99 & $(27.3)$ & 16 & (5.7) \\
\hline Individual & 0 & & 0 & & 0 & \\
\hline \multicolumn{7}{|l|}{ Instructional Grouping } \\
\hline Whole class & 954 & $(70.7)$ & 229 & $(63.1)$ & 225 & $(80.1)$ \\
\hline Small group & 106 & $(7.9)$ & 49 & $(13.5)$ & 6 & $(2.1)$ \\
\hline One-to-one & 2 & $(0.1)$ & 2 & $(0.6)$ & 0 & \\
\hline Independent & 268 & $(19.9)$ & 79 & $(21.8)$ & 49 & $(17.4)$ \\
\hline No instruction & 20 & $(1.5)$ & 4 & (1.1) & 1 & $(0.4)$ \\
\hline \multicolumn{7}{|l|}{ Instructional Task } \\
\hline Readers & 72 & $(5.3)$ & 19 & $(5.2)$ & 3 & (1.1) \\
\hline Workbooks & 2 & $(0.1)$ & 1 & $(0.3)$ & 1 & $(0.4)$ \\
\hline Worksheet & 197 & $(14.6)$ & 66 & $(18.2)$ & 58 & (20.6) \\
\hline Paper \& pencil & 83 & $(6.1)$ & 10 & $(2.8)$ & 9 & (3.2) \\
\hline Listen to lecture & 439 & $(32.5)$ & 108 & $(29.8)$ & 96 & $(34.2)$ \\
\hline Other media & 188 & $(13.9)$ & 54 & (14.9) & 71 & $(25.3)$ \\
\hline Discussion & 281 & $(20.8)$ & 84 & $(23.1)$ & 39 & $(13.9)$ \\
\hline Fetch/put away & 65 & $(4.8)$ & 14 & $(3.9)$ & 4 & (1.4) \\
\hline No task & 23 & $(1.7)$ & 7 & (1.9) & 0 & \\
\hline \multicolumn{7}{|l|}{ Instructional Activity (Subject matter) } \\
\hline Reading & 0 & & 0 & & 0 & \\
\hline Math & 322 & $(23.9)$ & 117 & $(32.2)$ & 0 & \\
\hline Spelling & 0 & & 0 & & 0 & \\
\hline Handwriting & 0 & & 0 & & 0 & \\
\hline Language & 312 & $(23.1)$ & 136 & $(37.5)$ & 13 & (4.6) \\
\hline Science & 269 & $(19.9)$ & 13 & $(3.6)$ & 67 & $(23.8)$ \\
\hline Social studies & 415 & $(30.7)$ & 88 & $(24.2)$ & 199 & $(70.8)$ \\
\hline Prevocational & 0 & & 0 & & 0 & \\
\hline Gross motor activities & 0 & & 0 & & 0 & \\
\hline Daily living \& community skills & 0 & & 0 & & 0 & \\
\hline Self-care & 0 & & 0 & & 0 & \\
\hline Arts/Crafts & 0 & & 0 & & 0 & \\
\hline Free time & 0 & & 0 & & 0 & \\
\hline Business/management & 10 & $(0.7)$ & 2 & $(0.6)$ & 0 & \\
\hline Transition & 21 & (1.6) & 7 & (1.9) & 2 & $(0.7)$ \\
\hline Music & 0 & & 0 & & 0 & \\
\hline Time out & 0 & & 0 & & 0 & \\
\hline No activity & 0 & & 0 & & 0 & \\
\hline Can't tell & 0 & & 0 & & 0 & \\
\hline Other & 0 & & 0 & & 0 & \\
\hline
\end{tabular}




\begin{tabular}{|c|c|c|c|c|}
\hline \multirow{2}{*}{$\begin{array}{l}\text { Variable Descriptions } \\
\text { Academic Response }\end{array}$} & $\begin{array}{l}\text { Total Intervals } \\
(\mathrm{N}=1350) \\
\text { Frequency (\%) }\end{array}$ & $\begin{array}{c}\text { No CM: } \\
\text { Only F4+F5 } \\
(\mathrm{N}=363) \\
\text { Frequency (\%) }\end{array}$ & \multicolumn{2}{|c|}{$\begin{array}{c}\text { CM: } \\
\text { Adaptations } \\
(\mathrm{N}=281) \\
\text { Frequency (\%) }\end{array}$} \\
\hline & & & & \\
\hline Writing & $250(18.5)$ & $52 \quad(14.3)$ & 83 & $(29.5)$ \\
\hline Task participation & $82 \quad(6.1)$ & $15 \quad(4.1)$ & 29 & $(10.3)$ \\
\hline Reading aloud & $5 \quad(0.4)$ & $1 \quad(0.3)$ & 0 & \\
\hline Reading silently & $174(12.9)$ & $33 \quad(9.1)$ & 31 & $(11.0)$ \\
\hline Talk academic & $24 \quad(1.8)$ & $9 \quad(2.5)$ & 3 & $(1.1)$ \\
\hline${ }^{2}$ No academic response & $815(60.4)$ & $253(69.7)$ & 135 & $(48.0)$ \\
\hline \multicolumn{5}{|l|}{ Task Management } \\
\hline Raising hand & $4 \quad(0.3)$ & 0 & 2 & $(0.7)$ \\
\hline Interacting appropriately & 0 & 0 & 0 & \\
\hline Manipulating materials & $66 \quad(4.9)$ & $16 \quad(4.4)$ & 9 & $(3.2)$ \\
\hline Moving & $9 \quad(0.7)$ & $4 \quad(1.1)$ & 0 & \\
\hline Talk management & $6 \quad(0.4)$ & $1 \quad(0.3)$ & 0 & \\
\hline Artention & $409 \quad(30.3)$ & $121 \quad(33.3)$ & 83 & $(29.5)$ \\
\hline aNo management & $854 \quad(63.3)$ & $221 \quad(60.9)$ & 187 & $(66.5)$ \\
\hline \multicolumn{5}{|l|}{ Competing Response } \\
\hline Aggression & 0 & 0 & 0 & \\
\hline Disrupt & 0 & 0 & 0 & \\
\hline Talk inappropriate & $14 \quad(1.0)$ & $9 \quad(2.5)$ & 0 & \\
\hline Looking around & $128 \quad(9.5)$ & $40 \quad(11.0)$ & 16 & $(5.7)$ \\
\hline Non-compliance & $39 \quad(2.9)$ & $14 \quad(3.9)$ & 6 & (2.1) \\
\hline Self-stimulation & $151 \quad(11.2)$ & $32 \quad(8.8)$ & 17 & $(6.0)$ \\
\hline Self-abuse & $3 \quad(0.2)$ & $1 \quad(0.3)$ & 1 & $(0.4)$ \\
\hline "No inappropriate behavior & $1,014 \quad(75.1)$ & 267 (73.6) & 241 & $(85.8)$ \\
\hline
\end{tabular}

aPresents nontargered student behavior variables.

small group variable was observed about six times more in the No CM group than the small group of the CM group $(2.1 \%)$ as the divided group variable in the No CM group was more observed in the divided group of the CM group. The oneto-one group and the no instruction variables were rarely observed in both the No CM and CM groups. For the instructional task category, the listen-to-lecture variable was the most frequently observed both under the No CM $(29.8 \%)$ and the CM $(34.2 \%)$ groups. It is interesting to note that the orher media variable was more than one and a half times more frequently observed in the CM group $(25.3 \%)$ than in that of the No CM group $(14.9 \%)$. On the other hand, the discussion variable was observed over one and half times more frequently in the No CM group $(23.1 \%)$ than the CM group (13.9\%). The workbook variable was the least observed in both the No CM $(0.3 \%)$ and the CM $(0.4 \%)$ groups. The no task variable was not observed in the CM group. Overall, most instructional activity was observed in core content area, math (23.9\%), language $(23.1 \%)$, science $(19.9 \%)$, and social studies $(30.7 \%)$, followed by transition and business management variables. However, overall distribution related to instructional activity was remarkably different depending on the presence of curriculum modifications. For example, the math activity variable was observed in 117 intervals $(32.2 \%)$ in the No CM group. However, there was no single interval observed related to the math activity variable in the CM group. In addition, the language variable was the most frequently observed in the No CM group $(37.5 \%)$. It was observed more than 8 times more often than the language variable in the $\mathrm{CM}$ group intervals $(4.6 \%)$. The language variable in the $\mathrm{CM}$ group was the least observed instructional activity, followed by the transition variable. The science 


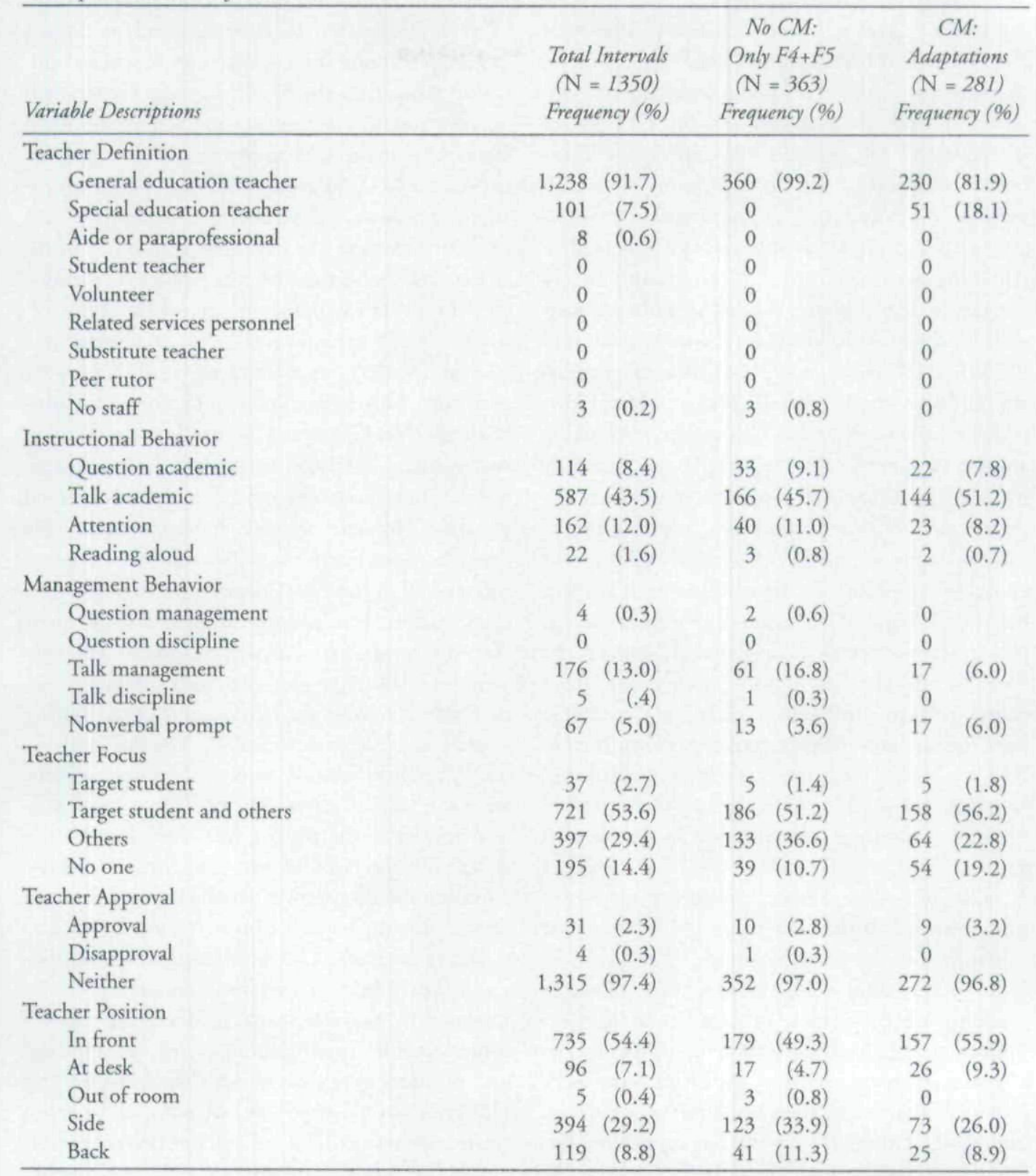

activity variable was observed only in $13(3.6 \%)$ intervals in the No CM group, whereas $23.8 \%$ of intervals were science activity in the $\mathrm{CM}$ group, which was about seven times more. The social studies variable was the most frequently observed in the CM group (199 intervals, $70.8 \%$ ), a greater amount than was observed in the No CM group (24.2\%).

Student Behavior Intervals. Table 4 illustrates descriptive statistics of student behavior intervals observed in three categories: academic response, task management, and competing response. In terms of academic response, the writing variable was the most frequently observed followed by reading silently, task participation, talk academic, and reading aloud variables in both the No CM and $\mathrm{CM}$ groups. More academic responses were observed in the CM group than in the No CM group except for talk academic-especially the writing $(29.5 \%)$ and task participation (10.3\%) 
variables, which were more than twice more often observed in the CM group intervals than the writing $(14.3 \%)$ and task participation $(4.1 \%)$ variables in the No CM group. For task management, the attention variable was the most frequently observed in both the No CM and the CM groups intervals $(33.3 \%$ and $29.5 \%$, respectively), distantly followed by the manipulating materials variable ( $4.4 \%$ and $3.2 \%$, respectively). The interacting appropriately variable was not observed in either the No CM nor the CM group. In terms of the competing response, the self-stimulation variable $(11.2 \%)$ was followed by the looking around (9.5\%), noncompliance $(2.9 \%)$, talk inappropriate $(1.0 \%)$, and self-abuse $(0.2 \%)$ variables. However, in the case of the No CM group, the looking around variable $(11.0 \%)$ was the most frequently observed, and it was almost twice more often observed than the looking around variable in the CM group (5.7\%). One-way ANOVA was employed to examine differences in each student behavior category (i.e., academic response, competing response, task management) between the No CM and the CM groups. As a result, there were significant differences in student academic response and compering response between the No $\mathrm{CM}$ and the CM groups. More academic responses $(M=.5196, S D=.50)$ were observed in the $\mathrm{CM}$ group than were observed in the No $\mathrm{CM}$ group $(M=.3030, S D=.46), F(1,642)=$ $32.479, p<.001$. Fewer competing responses were observed in the CM group $(M=.1423, S D$ $=.35)$ than in the No CM group $(M=.2645, S D$ $=.44), F(1,642)=14.453, p<.001$. That is, students were engaged in more academic responses and showed fewer student competing behaviors when curriculum modifications were provided than when there were not any curriculum modifications. There was no significant difference in student task management between the No CM and CM groups.

Teacher Behavior Intervals. Table 5 presents descriptive statistics of teacher behavior intervals observed about teacher definition, instructional behavior, management behavior, focus, approval, and position. Overall, general education teachers dominated class instruction during most observations (1,238 intervals, $91.7 \%)$. The intervals in which special education teachers were engaged in instructional behavior were just 101 intervals
(7.5\%) followed by aides or paraprofessionals ( 8 intervals, $0.6 \%$ ). General education teachers completely dominated in instructional behaviors $(99.2 \%)$ without any engagement of special education teachers in the No CM group. General education teachers were also observed as the main instructor in the CM group (81.9\%). However, unlike the No CM group intervals, special education teachers were the main instructors in $18.1 \%$ of observations in the CM group. In terms of instructional behavior, the talk academic variable was the most frequently observed $(43.5 \%)$ followed by the attention $(12.0 \%)$, question academic $(8.4 \%)$, and reading aloud $(1.6 \%)$ variables. This trend was exactly the same with both the No CM and CM groups. For teacher management behavior, overall, the talk management variable was the most frequently observed $(13.0 \%)$. However, the talk management variable was observed more than two and a half times more often in the No CM group than in the CM group. There were no intervals in which the question discipline variable was observed. Teachers were more likely to focus on both the target student (student with disabilities) and others during overall observations $(53.6 \%)$. The intervals in which teachers focused on only the target student were the least observed $(2.7 \%)$. The overall pattern related to the teacher focus variable did not differ with the No CM and CM group. Teachers' approval and disapproval variables were rarely observed during overall observations, $2.3 \%$ and $0.3 \%$, respectively. The most frequent teacher position observed was the front variable $(54.4 \%)$ followed by the side, back, at desk, and out-ofroom variables. This pattern of teacher approval and position were true of both the No CM and CM groups. One-way ANOVA was used to investigate differences in three teacher behavior categories (i.e., teacher instruction behavior, teacher management, teacher focus) between the No CM and $\mathrm{CM}$ groups. The result indicated that there was a significant difference in the teacher management variable. Fewer instances of teacher management $(M=.1212, S D=.33)$ were observed in the CM group than that of the No CM group $(M=$ $.2121, S D=.41), F(1,642)=9.325, p<.01$. In other words, teachers were more likely to engage in management behavior when no curriculum modifications were provided than when curricu- 
lum modifications were provided. There were no significant differences in the teacher instruction and teacher focus variables between the No CM and the CM groups.

\section{DISCUSSION}

As discussed earlier, curriculum modifications and teacher, student, and classroom ecological variables are important if students with disabilities are to achieve access to and progress in the general education curriculum. This study examined (a) whether curriculum modifications predicted student and teacher behavior in a general education classroom and (b) whether there are any differences in ecological, student, and teacher variables depending on the presence of curriculum modifications through ecobehavioral observations of 45 high school students with disabilities who received instruction in core content areas. As we predicted, the findings from this study supported the importance of curriculum modifications on teacher and student behaviors and suggested practices to enhance implementation of curriculum modifications to promote access to the general education curriculum for students with disabilities.

\section{THE IMPORTANCE OF CURRICULUM MODIFICATIONS}

In this study, the presence or implementation of curriculum modifications was a strong predictor of positive student academic responses. Student academic responses were observed more frequently when students were engaged in tasks linked to standards when any curriculum modification was present. Even when curriculum modifications were not observed, there was still a positive relationship between student engagement in off-grade standard activity (Only F4) and their academic responses. Having students engaged in on-grade standard activity without any curriculum modifications (Only F5) did not predict student academic responses. When students were engaged in off-grade or on-grade standard activities without any curriculum modifications present, they were likely to engage in behaviors that competed with active engagement. On the other hand, when students were engaged in tasks linked to standards-driven activities with curriculum modifications present, there were no relationships with competing responses. It is interesting to note that when students were engaged in tasks linked to a standard only with curriculum accommodations (e.g., the presence of a paraprofessional), then competing responses occurred. In addition to student academic and competing responses, teachers also engaged in fewer management behaviors when curriculum modifications were provided, as seen in the comparison of frequencies of teacher management behavior between the No $\mathrm{CM}$ and the CM groups.

\section{IMPLICATIONS AND PRACTICES TO \\ ENHANCE THE IMPLEMENTATION OF CURRICULUM MODIFICATIONS}

Given the importance of curriculum modifications and their positive effect on student and teacher behavior, it is important to make an effort to implement curriculum modifications in more effective ways to enhance access to the general education curriculum for students with disabilities. This study suggested several implications for practices for implementation of curriculum modifications.

Teacher Education and Collaboration. As seen in Table 5, and not surprisingly, general education teachers were the dominant instructors in general education classrooms in both the No CM and the $\mathrm{CM}$ groups. The CM group, however, included 51 intervals in which special education teachers worked as the primary teacher in the classroom being observed, whereas the No CM group contained no such intervals. This suggests, again not surprisingly, that the provision of curriculum modifications is a role performed primarily by special educators. It will be necessary, however, to disconnect the presence of a special educator and the provision of a curriculum modification if students with disabilities are to succeed in the general education curriculum. As such, training for general educators needs to prepare them to provide such curriculum modifications independent of the presence or absence of a special educator in the classroom.

Equally important is the involvement of paraprofessionals as educational supports for students with disabilities. Even though paraprofessionals were present in $62.2 \%$ of overall intervals, the intervals in which paraprofessionals directly 
interacted as, essentially, teachers with the target students was only $0.6 \%$ of total intervals. As such, they were not a factor in either the provision (or lack thereof) of curriculum modifications. Paraprofessionals can and should be trained to implement curriculum modifications.

Other Suggestions Pertaining to Curriculum Modifications. Along with teacher education issues, it is important to consider what other suggestions might be generated from the ecobehavioral analyses that would enhance access to the general education curriculum for students with disabilities. For one thing, it is important to extend the types of curriculum modifications that are used. In this study, as in other studies, curriculum augmentations (e.g., learning-to-learn strategies, self-directed learning strategies) were absent. In addition, the findings from this study showed a disproportionate use of curriculum modifications depending on subject area. For example, curriculum modifications were rarely present when students were involved in language arts and math; however, such supports were more prevalent during social studies and science instruction.

Next, according to previous studies related to ecological variables that affect students' academic engagement, small group or one-to-one support was more effective than entire group instruction (Hunt, Staub, Alwell, \& Goetz, 1994; McDonnell, Thorson, \& McQuivey, 1998; Rankin et al., 1999; Soukup et al., 2007; Vaughn et al., 2003). Unlike these previous studies, entire group instruction and whole class groupings were used more in this study when curriculum adaptations were provided.

Finally, findings from this study also suggest that the impact of teacher focus on students' behavior is different depending on students' age and needs. For example, previous studies examining younger students with disabilities found that teacher focus was an important factor affecting student academic responses or competing response (Soukup et al., 2007; Vyse \& Mulick, 1988), a finding not replicated in this study. This may not be surprising in that high school students are expected to work more independently than are younger students.

\section{LIMITATIONS}

There are several limitations that need to be considered when interpreting these findings. Because of the difficulty in recruiting subjects with disabilities who received instruction in core content areas in the general education classroom, the sample was not a random sample and the findings may not generalize to a broader population of students with disabilities. The lack of diversity in the sample further limits generalization. In addition, the lack of IQ data for students limits the degree to which we can identify disability-level effects. Also, the absence of curriculum augmentations provides information about practice, but limits what we can say about the role of curriculum modifications in student access and progress.

With regard to instrumentation, the Access CISSAR is an adapted version of the MS-CISSAR, and although psychometric data support the use of the latter, the Access version has not been evaluated for psychometric properties. We believe the potential negative impact of this is mitigated by three factors. First, the Access version consists of the (near) totality of the MS-CISSAR, without modification and, thus, shares the psychometric characteristics of the original instrument. Second, the added items were derived from research examining variables related to access to the general education curriculum (Wehmeyer et al., 2003). Third, observers undergo rigorous training and do not collect data until acceptable reliability data are obtained. As such, although we believe the instrument is both valid and reliable, findings need to be interpreted with the understanding that specific psychometric properties, such as test-retest reliability, have not been evaluated.

Finally, this study investigated changes on student and teacher variables depending on the presence of curriculum modifications. However, it did not examine the quality of teacher instruction and direct student academic achievement (e.g., GPA, test scores) beyond the student behaviors that were observed. However, given that ecobehavioral examination is a good tool to provide a "portrait" of natural settings, the findings in this study will suggest a snapshot of the real high school classroom including student and teacher behaviors and ecological variables depending on the presence of curriculum modifications and will provide im- 
plications for implementing effective curriculum modifications to ensure access to the general education curriculum for students with disabilities.

\section{REFERENCES}

Bashinski, S. M., \& Wehmeyer, M. L. (2002). Access CISSAR (Version 1.0) [Computer software]. Lawrence: University of Kansas.

Brophy, J., \& Good, T. (1986). Teacher behavior and student achievement. In M. Wittrock (Ed.), Handbook of research on teaching (pp. 340-370). New York: Macmillan.

Brown, W. H., Odom, S. L., Li, S., \& Zercher, C. (1999). Ecobehavioral assessment in early childhood programs: A portrait of preschool inclusion. The Journal of Special Education, 33, 138-153.

Browne, W. J., \& Rasbash, J. (2004). Multilevel modelling. In M. A. Hardy \& A. Bryman (Eds.), Handbook of data analysis (pp. 459-480). London: Sage.

Carta, J. J., Greenwood, R., Schulte, D., Arreaga-Mayer, \& Terry, B. (1988). Code for Instructional Structure and Student Academic Response: Mainstream version (MS-CISSAR). Kansas Ciry: University of Kansas, Bureau of Child Research, Juniper Gardens Children's Project.

Carvajal, S. C., Baumler, E., Harrist, R. B., \& Parcel, G. S. (2001). Multilevel models and unbiased test statistics for group based interventions: Examples from the safer choices study, Journal of Multivariate Research, 36(2), 185-205.

Duvall, S. F., Delquadri., J. C., \& Ward, D. L. (2004). A preliminary investigation of the effectiveness of homeschool instructional environments for students with attention deficit/hyperactivity disorder. School Psychology Review, 33, 140-158.

Dymond, S. K., \& Russell, D. L. (2004). Impact of grade and disability on the instructional context of inclusive classrooms. Education and Training in Developmental Disabilities, 39, 127-140.

Fisher, D., \& Nancy, F. (2001). Access to the core curriculum: Critical ingredients for student success. Remedial and Special Education, 22, 148-157.

Friedman, D. L., Cancelli, A. A., \& Yoshida, R. K. (1988). Academic engagement of elementary school children with learning disabilities. Journal of Psychology, 26, 327-340.

Greenwood, C., Schulte, D., Kohler, F., Dinwiddie, G., \& Carta, J. (1986). Assessment and analysis of ecobehavioral interaction in school settings. In R. J. Prinz (Ed.), Advances in behavioral assessment of children and families (pp. 69-98). Lincoln, NB: JAI Press.
Greenwood, C. R. (1991). Longitudinal analysis of time, engagement, and achievement in at-risk versus nonrisk students. Exceptional Children, 57, 521-535.

Greenwood, C. R., Arreaga-Mayer, C., \& Carta, J. J. (1994). Identification and translation of effective, teacher-developed instructional procedures for general practice. Remedial and Special Education, 15, 140-151.

Greenwood, C. R., Carta, J. J., Arreaga-Mayer, C., \& Rager, A. (1991). The behavior analyst consulting model: Identifying and validating naturally effective instructional procedures. Journal of Behavioral Education. 1, 165-191.

Greenwood, C. R., Carta, J. J., Kamps, D., Delquadri, J., Terry, B., Finney, R., et al. (1997). Ecobehavioral Assessment Systems Software (EBASS): Version 3.0 [Practitioner's Manual]. Kansas City: University of Kansas, Bureau of Child Research, Juniper Gardens Children's Project.

Greenwood, C. R., Carta, J. J., Kamps, D., Terry, B., \& Delquadri, J. (1994). Development and validation of standard classroom observation systems for school practitioners: Ecobehavioral Assessment Systems Software (EBASS). Exceptional Children, 61, 197-210.

Greenwood, C. R., Delquadri, J. C., \& Hall, R. V. (1989). Longitudinal effects of classwide peer tutoring. Journal of Educational Psychology, 81, 371-383.

Greenwood, C. R., \& Hou, L. (1995). Ecobehavioral Assessment Systems Software [Technical manual]. Lawrence: University of Kansas, Bureau of Child Research, Juniper Gardens Children's Project.

Guo, G., \& Zhao, H. (2000). Multilevel modeling for binary data. Annual Revieus of Sociology, 26, 441-462. Retrieved on August 29, 2005, from arjournals. annualreviews.org.

Hartmann, D. P., \& Woods, D. D. (1982). Observarional methods. In A. S. Bellack, M. Hersen, \& A. E. Kazdin (Eds.), International handbook of behavior therapy (pp. 109-138). New York: Plenum.

Hunt, P., Staub, D., Alwell, M., \& Goetz, L. (1994). Achievement by all students within the context of cooperative learning groups. The Journal of the Association for Persons with Severe Handicaps, 19, 290-301.

Janney, R., \& Snell, M. (2000). Teachers'guides to inclusive practices: Modifying schoolwork. Baltimore: Paul $\mathrm{H}$. Brookes.

Kame'cnui, E. J., \& Simmons, D. C. (1999). Toward successful inclusion of students with disabilities: The architecture of instruction. Arlington, VA: The Council for Exceptional Children.

Kamps, D., Greenwood, C. R., \& Leonard, B. (1991). Ecobehavioral assessment in classrooms serving chil- 
dren with autism and developmental disabilities. In R. Prinz (Ed.), Advances in behavior assessment of children and families (pp. 203-239). New York: Kingsley.

Kamps, D. M., Leonard, B. R., Dugan, E. P., Boland, B., \& Greenwood, C. R. (1991). The use of ecobehavioral assessment to identify naturally occurring effective procedures in classrooms serving children with autism and other developmental disabilities. Journal of Special Education, 1, 367-397.

Katz, J., Mirenda, P., \& Auerbach, S. (2002). Instructional strategies and educational outcomes for students with developmental disabilities in inclusive "multiple intelligences" and typical inclusive classrooms. Research \& Practice for Persons with Severe Disabilities, 27, 227-238.

Kenny, D. A., \& Judd, C. M. (1986). Consequences of violating the independence assumption in the analysis of variance. Psychological Bulletin, 99, 422, 431.

Kreft, Ita G.G. (1996). Are multilevel techniques necessary? An overview, including simulation studies. Los Angeles: California State University.

Lee, S., Amos, B. A., Gragoudas, S., Lee, Y., Shogren, K. A., Theoharis, R, et al. (2006). Curriculum augmentation and adaptation strategies to promote access to the general curriculum for students with intellectual and developmental disabilities. Education and Training in Developmental Disabilities, 41, 199-212.

Lee, S., Soukup, J. H., Little, T. D., \& Wehmeyer, M. L. (2009). Student and teacher variables contributing to access to the general education curriculum for students with intellectual and developmental disabilities. Journal of Special Education, 43, 29-44.

Lee, S., Wehmeyer, M. L., Palmer, S. B., Soukup, J. H., \& Little, T. D. (2008). Self-determination and access to the general education curriculum. Journal of Special Education, 42, 79-107.

Logan, K., Bakeman, R., \& Keefe, E. (1997). Effects of instructional variables on engaged behavior of students with disabilities in general education classroom. Exceptional Children, 64, 481-497.

Logan, K., \& Keefe, E. (1997). A comparison of instructional context, teacher behavior, and engaged behavior for students with severe disabilities in general education and self-contained elementary classrooms. Journal of the Association for Persons with Severe Disabilities, 22, 16-27.

Maas, C. J., \& Hox, J. J. (2004). Robustness issues in multilevel regression analysis. Statistica Neerlandica, 58(2), 127-137.

McDonnell, J., Thorson, N., \& McQuivey, C. (1998). The instructional characteristics of inclusive classes for elementary students with severe disabilities: An exploratory study. Journal of Behavioral Education, 8, 415-437.

McDonnell, J., Thorson, N., \& McQuivey, C. (2000). Comparison of the instructional contexts of students with severe disabilities and their peers in general education classes. The Association for Persons with Severe Handicaps, 25, 54-58.

Moineddin, R., Matheson, E. I., \& Glazier, R. H. (2007). A simulation study of sample size for multilevel Logistic regression models. Retrieved July 29, 2008, from http://www.biomedcentral.com/1471-2288/7/34

Nolet, V., \& McLaughlin, M. J. (2000). Accessing the general curriculum: Including students with disabilities in standards-based reform. Thousand Oaks, CA: Corwin.

Rabe-Hesketh, S., Toulopoulou, T., \& Murray, R. M. (2001). Multilevel modeling of cognitive function in schizophrenic patients and their first degree relatives. Multivariate Behavional Research, 36, 179-198.

Rankin, D. H., Logan, K. R., Adcock, J., Angelucci, J., Pittman, C., Sexstone, A. et al. (1999). Small group learning: Effects of including a student with intellectual disabilities. Journal of Developmental and Physical Disabilities, 11, 159-177.

Rasbash, J. (2007). What are multilevel models and why should I use them? Retrieved July 14, 2007, from the Center for Multilevel Modelling Web site: http:// www.cmm.bristol.ac.uk/learning-training/ multilevel-models/what-why.shtml

Roberson, L., Woolsey, M. L., Seabrooks, J., \& Williams, G. (2004a). An ecobehavioral assessment of the teaching behaviors of teacher candidates during their special education internship experiences. Teacher Education and Special Education, 27, 264-275.

Roberson, L., Woolsey, M. L., Seabrooks, J., \& Williams, G. (2004b). Data-driven assessment of teacher candidates during their internships in deaf education. American Annals of the Deaf, 148, 403-412.

Rose, D. H., \& Meyer, A. (2002). Teaching every student in the digital age: Universal design for learning. Alexandria, VA: Association for Supervision and Curriculum Development.

Ross, D. E., Singer-Dudek, J., \& Greer, R. D. (2005). The Teacher Performance Rate and Accuracy scale (TPRA): Training as Evaluation. Education and Training in Mental Retardation and Developmental Disabilities, 40, 411-423.

Salend, S. J. (2000). Strategies and resources to evaluate the impact of inclusion programs on students. Intervention, 35 (May), 264-270, 289. 
Sax, G. (1997). Principles of educational measurement and psychological measurement and evaluation (4th ed.). Belmont, CA: Wadsworth.

Singer, J. D. (1998). Using SAS PROC MIXED to fit multilevel modes, hierarchical models, and individual growth models. Journal of Educational and Behavioral Statistics, 24, 323-355.

Singer, J. D., \& Willett, J. B. (2003). Applied longitudinal data analysis: Modeling change and event occurrence. New York: Oxford University Press.

Soukup, J. H., Wehmeyer, M. L., Bashinski, S. M., \& Bovaird, J. (2007). Classroom variables and access to the general education curriculum for students with disabilities. Exceptional Children, 74, 101-120.

Vaughn, S., Linan-Thompson, S., Kouzekanani, K., Bryant, D. P., Dickson, H., \& Blozis, S. A. (2003). Reading instruction grouping for students with reading difficulties. Remedial and Special Education, 24, 301-315.

Vyse, S. A., \& Mulick, J. A. (1988). Ecobehavioral assessment of a special education classroom: Teacher-student behavioral covariation. Journal of Developmental and Physical Disabilities, 1, 201-206.

Wallace, T., Anderson, A. R., Bartholomay, T., \& Hupp, S. (2002). An ecobehavioral examination of high school classrooms that include students with disabilities. Exceptional Children, 68, 345-359.

Wehmeyer, M. L., Lance, D., \& Bashinski, S. (2002). Promoting access to the general curriculum for students with mental retardation: A multi-level model. Education and Training in Mental Retardation and Developmental Disabilities, 37, 223-234.

Wehmeyer, M. L., Lattin, D., \& Agran, M. (2001). Achieving access to the general curriculum for students with mental retardation: A curriculum decision-making model. Education and Training in Mental Retardation and Developmental Disabilities, 36, 327-342.

Wehmeyer, M. L., Latrin, D., Lapp-Rincker, G., \& Agran, M. (2003). Access to the general curriculum of middle-school students with mental retardation: An observational study. Remedial and Special Education, 24, 262-272.

Woolsey, M. L., Harrison, T. J., \& Gardner, R. (2004). A preliminary examination of instructional arrangements, teaching behaviors, levels of academic responding of deaf middle school students in three different educational settings. Education and Treatment of Children, 27, 263-279.

\section{ABOUT THE AUTHORS}

SUK-HYANG LEE, Full-Time Lecturer, Department of Special Education, Ewha Womans University, Seoul, Korea. MICHAEL L. WEHMEYER (CEC KS Federation), Professor; JANE H. soukup (CEC KS Federation), Research Assistant Professor; and Susan B. PALMer (CEC KS Federation), Research Associate Professor, Department of Special Education, University of Kansas, Lawrence.

Address correspondence to Suk-Hyang Lee, Department of Special Education, Ewha Womans University, 11-1 Daehyung-Dong, SeodaemunGu, Seoul, 120-750, Korea (e-mail:deepjoy@ ewha.ac.kr).

Manuscript received February 2008; accepted February 2009.

REGISTER TODAY for this quality CE Conference!

The

YOUNG CHILD with SPECIAL NEEDS

The National Conference Addressing Issues in Early Development: Birth to Five Years

\section{Orlando, FL • March 16-20, 2010}

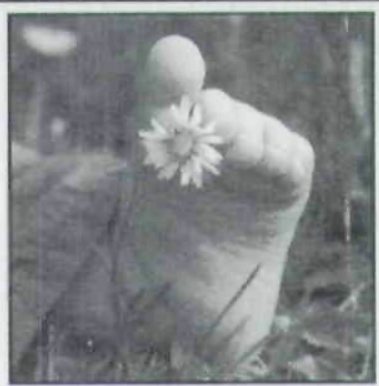

Online CE Library

View the Conference Content Onlinel Visit our website for details.

Email: info@cforums.com

Phone: (800) 377-7707, Ext. 5252 www.contemporaryforums.com

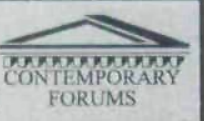


Copyright of Exceptional Children is the property of Council for Exceptional Children and its content may not be copied or emailed to multiple sites or posted to a listserv without the copyright holder's express written permission. However, users may print, download, or email articles for individual use. 